\title{
Cardiovascular Complications in Obstructive Sleep Apnea Syndrome
}

\author{
Ali Seyed Resuli ${ }^{1{ }^{*}}$ \\ ${ }^{1}$ Istanbul Yeni Yuzyil University, Istanbul, Turkey \\ "Corresponding author: Istanbul Yeni Yuzyil University, Faculty of Medicine, Eski Edirne Asfalti, No.: 653 Bahat Hastanesi Sultangazi, İstanbul, Turkey. Tel: +90-5322647435, \\ Email: a.s.resul@hotmail.com \\ Received 2019 March 12; Revised 2019 April 14; Accepted 2019 April 29.
}

\begin{abstract}
Obstructive sleep apnea syndrome (OSAS) is the most common respiratory disorder related to sleep. It is characterized by recurrent upper airway obstruction episodes and hypoxemia attacks during sleep. Cardiovascular complications are rather frequent in OSAS. This compilation study aimed to show cardiovascular pathologies occurring during OSAS in detail and emphasize the need of treating OSAS during the treatment of these pathologies
\end{abstract}

Keywords: Obstructive Sleep Apnea Syndrome, Cardiovascular, Complication

\section{Introduction}

Obstructive sleep apnea syndrome (OSAS) is a sleep disorder characterized by the halt of breathing as a result of repetitive complete (apne) or incomplete (hypopnea) obstruction of the upper airway, and hypoxia attacks during sleep (1). Apnea is a temporary stop of breathing for at least 10 seconds during sleep. Hypopnea is partial obstruction of air flow and is not a temporary stop of breathing (30\% reduction in breath amplitude, $4 \%$ reduction of oxygen saturation or $50 \%$ reduction in breath amplitude and $3 \%$ reduction of oxygen saturation for more than 10 seconds). The number of apnea-hypopne episodes per hour is called apnea-hpopnea index (AHI). As International Clinical Sleep Disorders -3 (AASM); based on AHI and oxygen saturation, severity of OSAS is classified as: (i) mild (AHI is 5 15 and oxygen saturation is $85 \%-95 \%$ ), (ii) moderate (AHI is $15-30$ and oxygen saturation is $65 \%-84 \%$ ), and (iii) severe (AHI is $>30$ and oxygen saturation is $<64 \%$ ) (2). OSAS incidence is increasing rapidly all around the world as a result of sedentary life style, smoking, alcohol use, obesity and aging. OSAS prevalence is 34\% in middle-aged men and $17 \%$ in middle-aged women (3). Although OSAS is common disease, its complications are not well known. Clinical findings and complications of OSAS vary. Among the primary complications of OSAS are cardio-vascular problems (hypertension, ischemic heart disease, pulmonary hypertension, heart failure, arrhythmia), neuro-psychological problems (stroke, epilepsy, headache, memory loss, anxiety, deceleration in decision-making ability, weakness, unwillingness, personality and behavior disorders), nephrological problems (nocturnal enuresis, proteinuria) and endocrine problems (loss of libido, impotence, menstrual disorder, hypothyroidism, metabolic syndrome) (4-7).

The most important side effects of OSAS are related to the cardiovascular system $(8,9)$. Systemic arterial hypertension (30\% - 60\%), pulmonary hypertension (20\% - 30\%), coronary artery disease (20\% - 30\%) and congestive heart failure $(5 \%-10 \%)$ are among the leading ones $(10,11)$. Cerebrovascular diseases due to OSAS are proportional to the effect of the cardiovascular system. Arrhythmia, high blood pressure, perfusion disorder and thrombus formation, development of cerebrovascular events are important reasons (12).

\section{Hemodynamic Changes in OSAS}

The effect of OSAS on cardiovascular system occurs in three stages. Stage I: The beginning of apnea, which is characterized by mild hypoxia and normal heart rate. Stage II: The late stage of apnea where hypoxia, heart rate, systolic and diastolic blood pressure increase significantly, and cardiac output decreases. Stage III: The end of apnea in which arousal (transition to sudden alertness during sleep) occurs, oxygen saturation increases with the onset of respiration, and heart rate and blood pressure reach the highest level $(9,13)$.

Upper airway obstruction that leads to OSAS also causes a significant increase in intrathoracic negative pressure. This increases catecholamine release, venous return to the heart and left ventricular post-load. This negative 
intrathoracic pressure increase during apnea causes hypertension and other cardiac complications $(14,15)$. In addition, catecholamine discharges and vasocostriction develop as a result of carotid chemoreceptors being stimulated by hypoxia occurring during apnea $(16,17)$.

\section{Systemic Hypertension}

Among patients with OSAS, 30\% - 50\% have hypertension and its severity increases in parallel with the severity of OSAS. The cause of hypertension in nearly $30 \%$ of the patients diagnosed with idiopathic hypertension was thought to have resulted from OSAS. Especially, morning tension is higher than evening tension in OSAS. Rhythm change in blood pressure is associated with apnea episodes in these patients. Only nocturnal hypertension attacks occur in mild OSAS, whereas daytime hypertension is accompanied in severe OSAS. Studies have showed that presence of OSAS is a risk factor for hypertension alone and that hypertension significantly decreases through OSAS treatment. Silverberg et al. reported that there was a significant improvement in daily blood pressure of the patients who were treated using continuous positive airway pressure (CPAP).

As a result of the increased sympathetic activation and vascular dysfunction, rhythmic increases in blood pressure can reach up to $20 \%$ in apnea episodes. Temporal elevations in systemic blood pressure as a result of hypoxemia, hypercapneic acidosis, intrathoracic pressure changes, arousal and reflex arterial vasoconstriction caused by sympathetic activity during or after apnea episodes decrease to normal levels with the restart of breathing. Contrary to normal people, no decrease is observed in blood pressure of OSAS patients during the night. Systemic blood pressure can reach the peak stage and be as high as being over 200/110 $\mathrm{mmHg}$ at the phase of arousal development and restart of breathing during apnea episodes which are recurrent and are characterized by profound oxygen desaturation. Increased sympathetic activation in patients with OSAS is observed not only while they sleep but also when they are awake. This shows that the changes occurring as a result of apnea during sleep also cause changes in the sensitivity of chemoreceptors and baroreceptors during wakefulness.

One of the possible salient mechanisms in recent years is vascular dysfunction, in other words, disruption of endothelial cell vasodilatation. Therefore, recent studies have focused on vasoactive substances released from vascular endothelium. As known, some vasoactive substances such as prostanoids, endothelin and nitric oxide are released from the vascular endothelium and these substances lead to vascular permeability changes, endothelial cell growth, cellular proliferation and mobility changes, angiogenesis and vascular tone changes through receptors in endothelial cells.

Studies conducted in recent years have showed that there is a relationship between OSAS and peripheral changes in peripheral vessels and dysfunction. One of these studies found nitric oxide-dependent vascular dilatation in OSAS patients. It was found in another study that when the synthesis of nitric oxide was pharmacologically inhibited, vasoconstriction increased in OSAS patients compared to those in the control group. As a result, it was suggested that vascular dysfunction might occur in OSAS patients and that this was not limited to reduction of nitric oxide release and dilator capacity, but also there could be a constructive effect. Although the cause of the constructive effect is not completely known, it is explained by the increase in sympathetic activation.

Other endothelium-mediated mediators associated with OSAS are adenosine and ekosanoids. Plasma adenosine levels were found to have increased in patients with OSAS. Krieger et al. showed that the ratio of 6-ketoprostaglandin PGF1 $\alpha$, which is a prostacyclin metabolite in urine, thromboxane B2/, thromboxane A2 metabolite in the urine, decreased in OSAS patients during the night and increased with CPAP treatment. Another interesting relationship was that endothelin-1(ET-1), which is a potent vasoconstrictor, was 2 - 3 times higher in OSAS patients than in the control group. However, there was no change in their levels with CPAP treatment.

The first findings show that the renal excretion of ET1 decreased in OSAS patients. Studies showed that the release of atrial natriuretic peptide (ANP) and the excretion of urine and sodium during sleep increased in OSAS patients. ANP suppresses the renin-angiotensin-aldosterone system and plasma renin activity decreases. These changes cause a decrease in blood volume, in other words, a decrease in blood pressure. Therefore, it is thought that it is a stabilizer for the increase of blood pressure, and in a sense, plays a protective role in OSAS patients. Using OSAS therapy, ANP levels return to normal, diuresis and natriuresis decrease, and renin and aldosterone release increases.

Age, obesity and basal blood pressure are the strongest predictor factors for resistant hypertension. The most common secondary resistant hypertensions are OSAS and kidney diseases. OSAS was found in $80 \%$ of patients with resistant hypertension (18-33).

\section{Coronary Artery Disease}

Several studies showed that OSAS is a serious risk factor for coronary artery disease. Many risk factors for OSAS 
and atherosclerosis (obesity, age, male sex, metabolic syndrome, smoking, increase in CRP levels and insulin resistance) are mutual. Hypoxia occurring in OSAS leads to both endothelial dysfunction and LDL oxidation due to oxidative stress. In addition, an increase has been shown in the levels of CRP, fibrinogen and interleukin-6 levels, each of which is known to be a risk factor for atherosclerosis in OSAS patients.

Conducting polysomnography (PSG), Mooe et al. found that $37 \%$ of men and 30\% of women had OSAS in patients who were diagnosed with coronary artery disease using angiography. Ischemic changes were observed in the ECG even in those who did not have previous history of coronary artery disease during the PSG. St depression is relatively frequent in OSAS patients and is decreased with CPAP therapy.

In a study conducted by Kohler et al. to investigate whether CPAP treatment rehabilitated vascular functions in patients with minimally symptomatic OSAS, they randomized a group of 253 patients with OSAS with minimal symptoms to CPAP treatment and standard care groups for 6 months and measured the arterial stiffness in 208 patients and endothelial functions with brachial artery dependent flow-mediated dilatation (FMD) method in 64 patients (augmentation index: AIx) by evaluating sleep status with Epworth sleepiness scale (ESS). In this study, it has been found that CPAP treatment does not have a significant effect on arterial stiffening (AIx, -1.4\%; 95\% CI, -3.6 to + 0.9\%; $\mathrm{P}=0.23$ ) according to the standard care group, but has improved endothelial functions (FMD, $+2.1 \%$; $95 \% \mathrm{CI},+1.0$ to + $3.2 \% ; \mathrm{P}=0.0001)$ and has decreased day time somnolence (ESS, -2.2; 95\% CI, -3.0 to -1.5; P = 0.0001). Researchers have stated that the highest level of correction on FMD has been found in patients using CPAP at night $>4 / \mathrm{s}(\mathrm{P}=0.013)$ and minimal symptomatic OSAS could be a risk factor for cardiovascular functions (34-41).

\section{Left Heart Failure}

Inspirium during apnea in OSAS increases intrathoracic negative pressure and increases venous blood return to the right heart. The overload in the right ventricle compresses the left ventricle and prevents it from being filled with enough blood. Combined with bradycardia during apnea, low stroke volume decreases cardiac output by $40 \%$ in average. In addition, cardiac afterload increases due to high negative intrathoracic pressure and this increases myocardial oxygen demand. The workload of the heart muscle increases, causing myocardial hypertrophy. Hypoxemia disrupts contraction ability of myocardium whose oxygen demand increased over time, which is characterized as heart failure. In a study, OSAS patients were found to have a larger left ventricular mass than the control group did. It was found in another study that $50 \%$ of the patients with OSAS had left ventricular hypertrophy and $20 \%$ had right ventricular hypertrophy $(10,18,19,21,42-$ 44).

\section{Right Heart Failure and Pulmonary Hypertension}

Pulmonary arterial pressure is stable during sleep in normal people. However, in OSAS patients, pulmonary vasoconstriction, pulmonary pressure increase and pulmonary hypertension (PHT) develop due to alveolar hypoxia occurring during apnea episodes. Prevalence of PHT was reported to be $10 \%-20 \%$ in mild OSAS patients and $50 \%$ in moderate to severe OSAS patients. PHT is not persistent in moderate OSAS patients and it regresses with treatment. Although there are differences between individuals, pulmonary arterial pressure can be as high as $80 / 50 \mathrm{mmHg}$, and the highest values are observed in the REM period where hypoxemia is the deepest. The rhythmic changes in pulmonary artery pressure are parallel to the changes in systemic blood pressure. These changes result from both the effects of inspiratory effort for closed airway on cardiopulmonary balance and pulmonary hypoxic vasoconstriction.

Cyanosis, right heart failure and chronic cor pulmonale findings may be detected in some OSAS patients. PHT that causes right heart failure is seen only in 10\% - 15\% of patients. Most of these patients are those with severe OSAS, overlap syndrome or obesity hypoventilation syndrome. It was also reported that chronic heavy drinking is more frequent in these patients.

PHT is faster in OSAS and chronic obstructive pulmonary disease (overlap syndrome) together.

PHT and right heart failure may be regressed using OSAS therapy. However, patients with irreversible right heart failure and cor pulmonale clinical features are those with end stage apnea. Unfortunately, this group of patients usually do not respond to aggressive medical and surgical treatment (5-7, 9, 45-47).

\section{Cardiac Arrhythmias}

Nocturnal arrhythmias are quite common in OSAS. During apnea, increased intrathoracic negative pressure stimulates N.vagus and hypoxemia stimulates the carotid body causing bradyarrhythmias. As a result of termination of apnea, vagal stimulation is eliminated and rebound tachyarrhythmias may occur. Concomitant coronary artery disease also provokes arrhythmias.

Studies have showed that supraventricular arrhythmias are generally related to autonomic nervous system 
activation, however, ventricular arrhythmias are related to hypoxemia. Oxygen saturation below $60 \%$ was found to increase the frequency of ventricular arrhythmias in patients with severe OSAS. Bradyarrhythmias usually occur in the REM phase of sleep. In general, $10 \%-30 \%$ of patients may have atrioventricular block, sinusal bradycardia and sinusal arrest. It was found in another comprehensive study that $7 \%$ of the OSAS patients had sinusal bradycardia, $11 \%$ had sinus arrest and $8 \%-20 \%$ had AV block. The most common tachyarrhythmia was early ventricular extra systole. Arrhythmias, coronary ischemia and myocardial infarction cause sudden death in severe OSAS patients.

In a recent review, it has been noted that the incidence of AF (atrial fibrillation) in patients with OSAS is around $40 \%-50 \%$ and it has been emphasized that that there have been changes in intrathoracic pressure during obstructive apneas, there have been sympathovagal fluctuations, there has been sympathetic and neurohumoral activation with electrophysiological and hemodynamic changes, and all these create an arrhythmogenic substrate by disrupting the atrial functions in the long term. In a study including 1210 patients with sleep apnea on whom examined the incidence of risk factors for AF and stroke, it has been observed that most patients (65.8\%) have severe sleep apnea $(\mathrm{AHI}>30)$ and $25.2 \%$ have mild to moderate sleep apnea (AHI: 5 - 30) and sleep apnea has not been detected in $8.8 \%$ of patients $(\mathrm{AHI}<5)$. It has been determined that patients with $\mathrm{AHI}>30$ are significantly older than those with $\mathrm{AHI}$ $<5$ (52.74 \pm 12.4 and $47.3 \pm 11.4, \mathrm{P}<0.001)$, and patients with higher body mass index $(33.83 \pm 10.1$ and $30.7 \pm 7.3, \mathrm{P}$ $<0.001$ ), with more frequent HT (38\% and 16\%, P < 0.001) have higher CHADS (congestive HF, HT, age, diabetes and past stroke) score $(0.59 \pm 0.8$ and $0.28 \pm 0.64, \mathrm{P}<0.001)$ and it has been stated that patients with severe sleep apnea have higher risk for AF and stroke when compared to those without sleep apnea (12, 48-51).

\section{Conclusions}

OSAS is rapidly increasing all around the world as a result of sedentary life style, smoking, alcohol use, obesity and aging. In parallel to OSAS, cardiovascular complications such as ischemic heart disease, arrhythmia and heart failure hypertension increases caused by this syndrome are also increasing.

As in our country, cardiovascular diseases are the leading cause of death in the world and cardiovascular diseases are frequently accompanied by sleep apnea or sleep apnea is the most common cause of cardiovascular cases. In addition, morbidity and mortality are significantly increased in the case of sleep apnea and cardio-vascular disease being together. All of the studies and current reviews have shed light on these issues. In addition to evaluating and controlling global (especially vascular) risk factors such as smoking, hypertension, obesity, dyslipidemia, diabetes and insulin resistance in patients with sleep apnea, and in addition to medical treatment and effective CPAP application, doing regular exercise and providing weight control is of great importance for preventing/decreasing cardiovascular complications in patients with sleep apnea. Also it is suggested that OSAS should also be treated in the treatment protocols of cardio-vascular diseases today.

\section{Footnotes}

Authors' Contribution: All stages of the study have been done by Ali Seyed Resuli.

Conflict of Interests: It is not declared by the author.

Ethical Approval: This is a review study, for that reason Ethics Committee approval is not required.

Financial Disclosure: Ali Seyed Resuli has nothing to disclose.

Funding/Support: The author has not support of the manuscript.

\section{References}

1. Azagra-Calero E, Espinar-Escalona E, Barrera-Mora JM, LlamasCarreras JM, Solano-Reina E. Obstructive sleep apnea syndrome (OSAS). Review of the literature. Med Oral Patol Oral Cir Bucal 2012;17(6):e925-9. doi: 10.4317/medoral.17706. [PubMed: 22549673]. [PubMed Central: PMC3505711]

2. Köktürk O. Uykuda solunum bozuklukları. Tuberkuloz ve Toraks Dergisi.1998;46(2):187-92.

3. Peppard PE, Young T, Barnet JH, Palta M, Hagen EW, Hla KM. Increased prevalence of sleep-disordered breathing in adults. Am J Epidemiol. 2013;177(9):1006-14. doi: 10.1093/aje/kws342. [PubMed: 23589584]. [PubMed Central: PMC3639722].

4. Fraser RS, Paré JP. Synopsis of diseases of the chest. 2 ed. Philadelphia: W.B. Saunders Company; 1994. doi: 10.1016/0954-6111(95)90239-2.

5. Phillipson EA. Sleep disorders. In: Murray JF, Nadel JA, editors. Textbook of respiratory medicine. Philadelphia: W.B Saunders Company; 1994. p. 2301-24.

6. Ferguson KA, Fleetham JA. Sleep-related breathing disorders. 4. Consequences of sleep disordered breathing. Thorax. 1995;50(9):9981004. doi: 10.1136/thx.50.9.998. [PubMed: 8539686]. [PubMed Central: PMC1021319].

7. Coleman J. Complications of snoring, upper airway resistance syndrome, and obstructive sleep apnea syndrome in adults. Otolaryngol Clin North Am. 1999;32(2):223-34. doi: 10.1016/S0030-6665(05)70126-2. [PubMed: 10385533].

8. Strauss RS, Browner WS. Risk for obstructive sleep apnea. Ann Intern Med.2000;132(9):758-9. doi:10.7326/0003-4819-132-9-20000502000014. [PubMed: 10787374].

9. Hedner J, Grote L. Cardiovascular consequences of obstructive sleep apnea. Eur Respir Mon. 1998;10:227-65. doi: 10.1097/HCO.0000000000000329.

10. Phillips B. Sleep-disordered breathing and cardiovascular disease. Sleep Med Rev. 2005;9(2):131-40. doi: 10.1016/j.smrv.2004.09.007. [PubMed: 15737791]. 
11. Parish JM, Somers VK. Obstructive sleep apnea and cardiovascular disease. Mayo Clin Proc. 2004;79(8):1036-46. doi: 10.4065/79.8.1036. [PubMed: 15301332].

12. Toraldo DM, Peverini F, De Benedetto M, De Nuccio F. Obstructive sleep apnea syndrome: Blood viscosity, blood coagulation abnormalities, and early atherosclerosis. Lung. 2013;191(1):1-7. doi: 10.1007/s00408012-9427-3. [PubMed: 23076780].

13. Weiss JW, Launois SH, Anand A, Garpestad E. Cardiovascular morbidity in obstructive sleep apnea. Prog Cardiovasc Dis. 1999;41(5):367-76. doi:10.1053/pcad.1999.0410367. [PubMed:10406330].

14. Shiomi T, Guilleminault C, Stoohs R, Schnittger I. Leftward shift of the interventricular septum and pulsus paradoxus in obstructive sleep apnea syndrome. Chest. 1991;100(4):894-902. doi: 10.1378/chest.100.4.894.

15. Virolainen J, Ventila $M$, Turto $H$, Kupari $M$. Influence of negative intrathoracic pressure on right atrial and systemic venous dynamics. Eur Heart J. 1995;16(9):1293-9. doi: 10.1093/oxfordjournals.eurheartj.a061088. [PubMed: 8582394].

16. Cifkova R, Erdine S, Fagard R, Farsang C, Heagerty AM, Kiowski $\mathrm{W}$, et al. Practice guidelines for primary care physicians: 2003 ESH/ESC hypertension guidelines. J Hypertens. 2003;21(10):1779-86. doi: 10.1097/01.hjh.0000084773.37215.1b. [PubMed:14508180].

17. Fujita S. Surgical treatment of obstructive sleep apnea. UPP and lingualplasty (laser midline glossectomy). In: Guilleminault C, Partinen $\mathrm{M}$, editors. Obstructive sleep apnea syndrome: Clinical research and treatment. New York: Raven Press; 1990. p. 129-51.

18. Aldrich MS. Sleep medicine. New York: Oxford University Press;1999. p. 202-36.

19. Anstead M, Phillips B. The spectrum of sleep-disordered breathing. Respir Care Clin N Am. 1999;5(3):363-77. viii. [PubMed: 10419581].

20. Peter JH, Koehler U, Grote L, Podszus T. Manifestations and consequences of obstructive sleep apnoea. Eur Respir J. 1995;8(9):1572-83. [PubMed: 8575587].

21. Redline S, Strohl KP. Recognition and consequences of obstructive sleep apnea hypopnea syndrome. Clin Chest Med. 1998;19(1):1-19. doi: 10.1016/S0272-5231(05)70428-7. [PubMed: 9554214].

22. Strohl KP, Redline S. Recognition of obstructive sleep apnea. Am J Respir Crit Care Med. 1996;154(2 Pt 1):279-89. doi: 10.1164/ajrccm.154.2.8756795. [PubMed: 8756795].

23. Weiss JW, Remsburg S, Garpestad E, Ringler J, Sparrow D, Parker JA. Hemodynamic consequences of obstructive sleep apnea. Sleep. 1996;19(5):388-97. doi:10.1093/sleep/19.5.388. [PubMed: 8843530].

24. Bresnitz EA, Goldberg R, Kosinski RM. Epidemiology of obstructive sleep apnea. Epidemiol Rev. 1994;16(2):210-27. doi: 10.1093/oxfordjournals.epirev.a036151. [PubMed: 7713177].

25. Carlson JT, Hedner JA, Ejnell H, Peterson LE. High prevalence of hypertension in sleep apnea patients independent of obesity. Am J Respir Crit Care Med. 1994;150(1):72-7. doi: 10.1164/ajrccm.150.1.8025776. [PubMed: 8025776].

26. Fletcher EC. Sympathetic activity and blood pressure in the sleep apnea syndrome. Respiration. 1997;64 Suppl 1:22-8. doi: 10.1159/000196732. [PubMed: 9380957].

27. Guilleminault C, Robinson A. Sleep-disordered breathing and hypertension: Past lessons, future directions. Sleep. 1997;20(9):806-11. doi: 10.1093/sleep/20.9.806. [PubMed: 9406332].

28. Guilleminault C. Clinical features and evaluation of obstructive sleep apnea. In: Kryger MH, Roth T, Dement WC, editors. Principles and practice of sleep medicine. Philadelphia: W.B. Saunders Company; 1994. p. 667-77.

29. Hoffstein V. Blood pressure, snoring, obesity, and nocturnal hypoxaemia. The Lancet. 1994;344(8923):643-5. doi: 10.1016/s01406736(94)92084-2.

30. Mooe T, Rabben T, Wiklund U, Franklin KA, Eriksson P. Sleepdisordered breathing in men with coronary artery disease. Chest 1996;109(3):659-63. doi: 10.1378/chest.109.3.659. [PubMed: 8617073]

31. Lloyd-Jones DM, Evans JC, Larson MG, O’Donnell CJ, Roccella EJ, Levy D.
Differential control of systolic and diastolic blood pressure : Factors associated with lack of blood pressure control in the community. Hypertension. 2000;36(4):594-9. doi: 10.1161/01.HYP.36.4.594. [PubMed: 11040241].

32. Lloyd-Jones DM, Evans JC, Larson MG, Levy D. Treatment and control of hypertension in the community: A prospective analysis. Hypertension. 2002;40(5):640-6. doi: 10.1161/01.HYP.0000035855.44620.DA. [PubMed: 12411456].

33. Calhoun DA, Jones D, Textor S, Goff DC, Murphy TP, Toto RD, et al. Resistant hypertension: Diagnosis, evaluation, and treatment. A scientific statement from the American Heart Association Professional Education Committee of the Council for High Blood Pressure Research. Hypertension. 2008;51(6):1403-19. doi: 10.1161/HYPERTENSIONAHA.108.189141. [PubMed: 18391085].

34. Mooe T, Rabben T, Wiklund U, Franklin KA, Eriksson P. Sleepdisordered breathing in women: Occurrence and association with coronary artery disease. Am J Med. 1996;101(3):251-6. doi: 10.1016/S0002-9343(96)00122-2. [PubMed: 8873485].

35. Andreas S, Schulz R, Werner GS, Kreuzer H. Prevalence of obstructive sleep apnoea in patients with coronary artery disease. Coron Artery Dis.1996;7(7):541-5. doi:10.1016/j.jsha.2015.03.004. [PubMed: 8913673].

36. Schafer H, Koehler U, Ploch T, Peter JH. Sleep-related myocardial ischemia and sleep structure in patients with obstructive sleep apnea and coronary heart disease. Chest. 1997;111(2):387-93. doi: 10.1378/chest.111.2.387. [PubMed: 9041987].

37. Yokoe T, Minoguchi K, Matsuo H, Oda N, Minoguchi H, Yoshino G, et al. Elevated levels of C-reactive protein and interleukin- 6 in patients with obstructive sleep apnea syndrome are decreased by nasal continuous positive airway pressure. Circulation. 2003;107(8):1129-34. doi: 10.1161/01.CIR.0000052627.99976.18. [PubMed: 12615790].

38. Kiely JL, McNicholas WT. Cardiovascular risk factors in patients with obstructive sleep apnoea syndrome. Eur Respir J. 2000;16(1):128-33. doi: 10.1136/thx.2003.018739. [PubMed:10933098].

39. Punjabi NM, Sorkin JD, Katzel LI, Goldberg AP, Schwartz AR, Smith PL. Sleep-disordered breathing and insulin resistance in middle-aged and overweight men. Am J Respir Crit Care Med. 2002;165(5):677-82. doi: 10.1164/ajrccm.165.5.2104087. [PubMed: 11874813].

40. Schmidt-Nowara WW, Coultas DB, Wiggins C, Skipper BE, Samet JM. Snoring in a Hispanic-American population. Risk factors and association with hypertension and other morbidity. Arch Intern Med. 1990;150(3):597-601. doi: 10.1001/archinte.1990.00390150089017. [PubMed: 2310278].

41. Kohler M, Craig S, Pepperell JCT, Nicoll D, Bratton DJ, Nunn AJ, et al. CPAP improves endothelial function in patients with minimally symptomatic OSA: Results from a subset study of the MOSAIC trial. Chest. 2013;144(3):896-902. doi: 10.1378/chest.13-0179. [PubMed: 23702567].

42. Hedner J, Ejnell H, Caidahl K. Left ventricular hypertrophy independent of hypertension in patients with obstructive sleep apnoea.Journal of Hypertension.1990;8(10):941-6. doi: 10.1097/00004872199010000-00009.

43. Laaban JP, Cassuto D, Orvoen-Frija E, Iliou MC, Mundler O, Leger $\mathrm{D}$, et al. Cardiorespiratory consequences of sleep apnoea syndrome in patients with massive obesity. Eur Respir J. 1998;11(1):20-7. doi: 10.1183/09031936.98.11010020. [PubMed: 9543265].

44. Noda A, Okada T, Yasuma F, Nakashima N, Yokota M. Cardiac hypertrophy in obstructive sleep apnea syndrome. Chest. 1995;107(6):1538-44. doi: 10.1378/chest.107.6.1538. [PubMed: 7781343].

45. Chaouat A, Weitzenblum E, Krieger J, Oswald M, Kessler R. Pulmonary hemodynamics in the obstructive sleep apnea syndrome. Chest.1996;109(2):380-6. doi: 10.1378/chest.109.2.380.

46. Kessler R, Chaouat A, Weitzenblum E, Oswald M, Ehrhart M, Apprill $M$, et al. Pulmonary hypertension in the obstructive sleep apnoea syndrome: prevalence, causes and therapeutic consequences. Eur Respir J.1996;9(4):787-94. doi: 10.1086/679995. [PubMed: 8726947]. 
47. Robinson A, Guilleminault C. Obstructive sleep apnea syndrome. In: Chokroverty S, editor. Sleep disorders medicine. Boston: ButterworthHeinemann; 1999. p. 331-54

48. Shepard JW Jr, Garrison MW, Grither DA, Dolan GF. Relationship of ventricular ectopy to oxyhemoglobin desaturation in patients with obstructive sleep apnea. Chest. 1985;88(3):335-40. doi: 10.1378/chest.88.3.335. [PubMed: 2411477].

49. Guilleminault C, Connolly SJ, Winkle RA. Cardiac arrhythmia and conduction disturbances during sleep in 400 patients with sleep apnea syndrome. Am J Cardiol. 1983;52(5):490-4. doi: 10.1016/0002-
9149(83)90013-9. [PubMed: 6193700].

50. Hohl M, Linz B, Bohm M, Linz D. Obstructive sleep apnea and atrial arrhythmogenesis. Curr Cardiol Rev. 2014;10(4):362-8. doi: 10.2174/1573403X1004140707125137. [PubMed: 25004989]. [PubMed Central: PMC4101201].

51. Valenza MC, Baranchuk A, Valenza-Demet G, Munoz-Casaubon T, Martin-Navajas JA, Healey J. Prevalence of risk factors for atrial fibrillation and stroke among 1210 patients with sleep disordered breathing. Int J Cardiol. 2014;174(1):73-6. doi: 10.1016/j.ijcard.2014.03.156. [PubMed: 24726170]. 